\title{
CRITÉRIO DE ALVARADO PARA DIAGNÓSTICO DE APENDICITE AGUDA INFANTIL
}

\author{
ALVARADO'S CRITERIA FOR DIAGNOSIS OF CHILDREN'S ACUTE \\ APENDICITIS
}

Bruno César Fernandes ${ }^{1}$, Raquel Borges de Barros Primo ${ }^{2}$, Anny Karoliny das

Chagas Bandeira ${ }^{3}$, Mariella Rodrigues da Silva ${ }^{4}$, Carolina Calixto de Souza Andrade ${ }^{5}$

${ }^{1}$ Empresa Brasileira de Serviços Hospitalares-Hospital Universitário da Grande Dourados, Dourados, Mato Grosso do Sul, Brasil.

${ }^{2}$ Universidade Federal da Grade Dourados - UFGD, Dourados, Mato Grosso do Sul, Brasil.

${ }^{3}$ Centro Universitário Jorge Amado, Salvador, Bahia, Brasil.

${ }^{4}$ Empresa Brasileira de Serviços Hospitalares-Hospital Universitário da Grande Dourados, Dourados, Mato Grosso do Sul, Brasil.

${ }^{5}$ Hospital Universitário Professor Edgard Santos-Hospital das clínicas, Salvador, Bahia, Brasil.

\section{RESUMO}

O abdome agudo em crianças é uma condição que causa grande aflição aos pais, e a apendicite é sua causa mais comum, sendo mais frequente na idade escolar. Esta patologia é causa de inúmeros atendimentos em hospitais públicos e particulares em todo o mundo,e traz diversas complicaçôes. É importante que a equipe de saúde esteja ciente da possibilidade de apendicite em crianças, devido a sua alta incidência e dificuldade em estabelecer o seu diagnóstico, pelo fato de os sintomas serem inespecíficos e haver diferentes apresentaçóes clínicas. Objetivo: explicar a importância do critério de Alvarado para o diagnóstico de apendicite aguda infantil. Metodologia: Trata-se de uma revisão bibliográfica integrativa, em artigos publicados nas bases de dados PubMed, Biblioteca Virtual em Saúde e Google Acadêmico. Para a busca de dados foram utilizados os descritores "Abdome agudo", "Apendicite", "Crianças" e a palavra-chave "Escore de Alvarado". Os dados foram coletados em dezembro de 2020. Resultados: Foram selecionados 16 artigos como amostra final de análise da revisão sendo seis em inglês, nove em português e um em espanhol. Conclusão: Através desta revisão pode-se concluir que o uso do Escore de Alvarado para o diagnóstico de apendicite aguda em crianças é útil e eficaz, evitando-se o uso de exames de imagem em pacientes que apresentem escore acima de 7 nessa escala.

Descritores: Abdome agudo; Apendicite aguda; Escore de Alvarado; Crianças. 


\section{ABSTRACT}

Acute abdomen in children is a condition that causes great distress to parents, and appendicitis is its most common cause, being more frequent at school age. This pathology is the cause of numerous visits to public and private hospitals around the world, and brings several complications. It is important that the health team is aware of the possibility of appendicitis in children, due to its high incidence and difficulty in establishing its diagnosis, because the symptoms are nonspecific and there are different clinical presentations. Objective: to explain the importance of the Alvarado criterion for the diagnosis of acute childhood appendicitis. Methodology: This is an integrative bibliographic review, in articles published in the PubMed, Virtual Health Library and Google Scholar databases. For the search for data, the descriptors "Acute abdomen", "Appendicitis", "Children" and the keyword "Alvarado score" were used. Data were collected in December 2020. Results: 16 articles were selected as the final sample for analysis of the review, six in English, nine in Portuguese and one in Spanish. Conclusion: Through this review it can be concluded that the use of the Alvarado Score for the diagnosis of acute appendicitis in children is useful and effective, avoiding the use of imaging tests in patients with a score above 7 on this scale

Descriptors: Acute abdomen; Acute appendicitis; Alvarado score; child.

\section{INTRODUÇÃO}

A apendicite aguda é a causa mais comum de abdome cirúrgico em crianças, tratando-se de um processo patológico de origem inflamatória que ocorre em qualquer faixa etária, do recém-nascido ao idoso, sendo mais comum na idade escolar. Esta patologia é causa de inúmeros atendimentos em hospitais públicos e particulares do mundo, e ainda promove diversas complicaçóes. Essa condição já era relatada no antigo Egito, e foi discutida em pleno Renascimento da Europa Ocidental, quando o Apêndice Cecal foi descoberto como entidade anatômica ${ }^{1}$.

Embora seja comum na infância e adolescência, a doença também tem prevalência em adultos jovens (19 a 44 anos), principalmente no sexo masculino ${ }^{2}$. A taxa de prevalência global da doença é de aproximadamente 7\% e o pico de incidência varia de acordo com o gênero e a faixa etária de crianças e adolescentes, sendo de 10-14 anos no sexo feminino e entre 15-19 anos no sexo masculino ${ }^{2}$.

Em um contexto histórico cabe dizer que a primeira remoção cirúrgica do apêndice foi realizada por Amayand em 1735, sendoJames Parkinsono primeiro no idioma inglês a descrever cientificamente a patologia da apendicite ${ }^{1}$. Ele descreveu detalhadamente, em 1812, o caso fatal de um de seus pacientes, um garoto de 5 anos, que ele havia observado por algum tempo, com problemas de saúde, mas não fez nenhuma queixa em particular, até dois dias antes de sua morte, quando passou, subitamente, a apresentar vômitos e grande prostração. $\mathrm{O}$ abdômen ficou muito túrgido e dolorido quando pressionado, o 
rosto pálido e o pulso quase imperceptível. A morte, precedida por extrema inquietação e delírio, ocorreu dentro de 24 horas $^{3}$.

Pearn et al. ${ }^{3}$ explicam queParkinson3 realizou a autópsia do menino do caso citado, e descreveu suas descobertas dizendo haver uma ligeira adesão entre o peritônio que cobre as vísceras e a parede do abdômen, onde as vísceras, independentemente da inflamação de sua cobertura peritoneal, apareciam em um estado perfeitamente saudável, com exceção do apêndice vermiforme do ceco. Ainda conforme os autores, Parkinson ${ }^{4}$ informou que nenhuma aparência doentia foi vista próxima ao ceco, porém, cerca de uma polegada de sua extremidade estava consideravelmente aumentada e espessada, sua superfície interna ulcerada e uma pequena abertura de ulceraçáo foi encontrada no início da parte doente, por volta da parte central do apêndice, através da qual parecia que um fluido fino, de cor escura e altamente fétido havia vasado para a cavidade abdominal. Ao abrir o apêndice, objetos endurecidos foram encontrados impactados na parte que ficava entre a abertura e a parte do apêndice.

Ainda atualmente, a apendicite é de grande importância etoda equipe de saúde deve estar ciente da possibilidade de apendicite em crianças, em decorrênciade sua alta incidência e dificuldade em estabelecer o seu diagnóstico, devido aos sintomas serem inespecíficos e possuir diferentes apresentaçóes clínicas 5 .

Há uma grande problemática quando a apendicite acomete crianças pré-escolares e neonatos. Nessas faixas menores os pacientes poderão apresentar sintomas mais atípicos, sendo confundidos com gastroenterites, podendo evoluir de maneira acelerada para complicaçóes mais graves como perfuração, abscessos e necrose ${ }^{6}$. É de conhecimento que em crianças menores de cinco anos de idade a incidência de apendicite costuma ser menor, porém, seu diagnóstico clínico é bem mais complicado ${ }^{1}$, isto se explica em parte pelas características anatômicas que estas crianças apresentam, como o omento curto, incapacitando o bloqueio eficaz dos processos infecciosos intraperitoneais evoluindo de maneira mais rápida a quadros sépticos ${ }^{6}$.

O tempo de diagnóstico em pacientes pré-escolares e neonatos nos serviços hospitalares é de suma importância, mas ainda existem algumas barreiras no processo de diagnóstico da doença, como dificuldade de comunicação e habilidades de profissionais ao exame físico ao se deparar com um abdome agudo em crianças, bem como, na identificaçáo dos sintomas do quadro.Portanto, é preciso ter o conhecimento dos principais transtornos abdominais em crianças, com suas apresentaçóes especificas, diagnósticos, e tratamentos com ações minimamente invasivas com os menores custos possíveis ${ }^{6}$.

Nesse caso, o exame de escolha para melhor auxiliar no diagnóstico da Apendicite Aguda é a tomografia computadorizada com contraste, pois a mesma apresenta alta sensibilidade e especificidade ${ }^{7}$. Contudo, é notório que seu uso apresenta um alto custo 
ao sistema público de saúde e poderá proporcionar a criança alta quantidade de radiação, causando efeitos nocivos a diferentes células.

Em consequência da dificuldade, seja ela por recursos financeiros no sistema público de saúde, ou por incapacidade do serviço hospitalar, de disponibilizar facilmente exames de imagem e com o intuito de facilitar a identificação de abdome inflamatório pelo exame físico, foram criadas diferentes escalas de classificação para diagnóstico da apendicite aguda $\mathrm{a}^{5,7}$.

Em 1986, o Dr. Alfredo Alvarado observou sinais e sintomas mais frequentes para realização do diagnóstico de Apendicite Aguda, e a partir de então desenvolveu, por meio de estudos, sua própria escala ${ }^{8}$. Diversos estudos ${ }^{5,7,8}$ mostram a associação entre o critério de pontuação do Escore de Alvarado e a confirmação diagnóstica da Apendicite Aguda. No estudo de Nascimento et al. ${ }^{7}$ o escore de Alvarado demonstrou ser bom método para triagem diagnóstica na Apendicite Aguda, utilizando como ponto de corte pontuaçóes maiores ou iguais a seis que foram associadas a uma probabilidade maior de confirmação diagnóstica ao histopatológico.

Sendo assim, a relevância social dessa pesquisa se justifica pelo fato da apendicite aguda representar a afecção cirúrgica mais comum no mundo, tendo incidência elevada principalmente na faixa etária escolar, entre 10 e 20 anos de idade. O diagnóstico deverá ser realizado com base na avaliação clínica do paciente e é condição emergente em crianças, porém seu diagnóstico oportuno e precoce permanece uma problemática ${ }^{6}$.

Diante do exposto, esta revisão teve como obetivo determinar a importância do critério de Alvarado para o diagnóstico de apendicite aguda infantil.

\section{METODOLOGIA}

O estudo se desenvolveu através de uma revisão bibliográfica integrativa, com a coleta de dados em artigos publicados, pesquisados através das bases de dados PubMed, Biblioteca Virtual em Saúde e Google Acadêmico. Os critérios de inclusão para essa revisão foram artigos com texto gratuito disponível na íntegra, em português, espanhol e/ou inglês sem limitação de data de publicação, ou seja, os estudos publicados em todo o período permitido pelas bases de dados selecionadas, pois o propósito foi abranger o maior número de artigos possíveis. Excluíram-se da amostra, permanecendo apenas uma vez, as repetiçóes e os documentos que não atenderam ao objetivo de pesquisa.

Para a seleção dos artigos foi efetuada consulta aos Descritores em Ciência da Saúde (DeCS), sendo identificados, selecionados e utilizados os seguintes descritores em português: "Abdome agudo", "Apendicite" e "Crianças". Com o interesse em analisar uma produção abrangente acerca de publicaçóes relacionada a temática dessa revisão e com o intuito de ampliar a amostra de análise, foi também utilizada, como estratégia de busca, a 
palavra-chave "Escore de Alvarado", tendo como eixo norteador os critérios de inclusão e exclusão, previamente estabelecidos para manter a coerência na busca dos artigos e evitar possíveis vieses. Tais termos foram cruzados a partir dos operadores booleanos AND ou OR.

Em dezembro de 2020, portanto, foi realizada as buscas utilizando os descritores e a palavra-chave nas bases dedados selecionadas nesta revisão.

Após uma pré-seleção dos artigos resultantes destas buscas, foram feitas leituras dos títulos e resumos da amostra total, aplicando-se os critérios de inclusão e exclusão.

Após perfazer este processo, foram selecionados 16 artigos como amostra final de análise da revisão. Do material obtido, procedeu-se à leitura minuciosa de seus conteúdos com intuito de aprofundar o conhecimento sobre o tema e atingir o objetivo proposto.

Os artigos selecionados para revisão foram organizados por meio de instrumento, não validado, elaborado pelos autores, contendo: título, ano de publicação, categoria e enfoque do estudo com o objetivo de sumarizar, extrair e proceder a análise dos dados.

\section{RESULTADOS E DISCUSSÃO}

Foram selecionados 16 artigos científicos como fonte de dados para o presente estudo, sendo seis em inglês, nove em português e um em espanhol. Os resultados das publicaçóes selecionadas nesta revisão estão descritos no Quadro 1.

\begin{tabular}{|c|c|c|c|c|}
\hline \multicolumn{5}{|c|}{ Quadro 1. Sumarizaçáo dos artigos selecionados para a revisáo de literatura. } \\
\hline No & Título do estudo & $\begin{array}{c}\text { Ano de } \\
\text { publicaçáo }\end{array}$ & $\begin{array}{l}\text { Categoria } \\
\text { do estudo }\end{array}$ & Enfoque do estudo \\
\hline 1 & $\begin{array}{l}\text { Case of diseased } \\
\text { vermiform appendix }\end{array}$ & 1812 & $\begin{array}{l}\text { Relato de } \\
\text { caso }\end{array}$ & $\begin{array}{l}\text { Relato de um caso clínico de evolução para óbito de uma } \\
\text { criança de } 5 \text { anos com acometimento do apêndice vermiforme. } \\
\text { É realizada a descrição dos sinais e sintomas da criança nesse } \\
\text { período de } 72 \text { horas até o óbito. }\end{array}$ \\
\hline 2 & $\begin{array}{l}\text { A apendicite na } \\
\text { síndrome de abdômen } \\
\text { agudo }\end{array}$ & 1942 & $\begin{array}{l}\text { Relato } \\
\text { de caso e } \\
\text { experiência } \\
\text { com } \\
\text { narrativa } \\
\text { empírica }\end{array}$ & $\begin{array}{l}\text { Descrição dos princípios fundamentais e as noçóes orientadoras } \\
\text { capazes de guiar o médico no diagnóstico e tratamento } \\
\text { da apendicite aguda. Lembraremos, entretanto, que tais } \\
\text { conhecimentos devem sempre estar, aliados a uma boa } \\
\text { experiência clínica, pois a capacidade de identificar com } \\
\text { precisão e cuidar proveitosamente das diferentes moléstias não } \\
\text { se adquire em palestras, mas pelo contato continuo e observação } \\
\text { racional dos doentes. }\end{array}$ \\
\hline 3 & $\begin{array}{l}\text { James Parkinson }(1755- \\
\text { 1824): a pioneer of } \\
\text { child care. }\end{array}$ & 2001 & $\begin{array}{l}\text { Revisão de } \\
\text { literatura }\end{array}$ & $\begin{array}{l}\text { Estudo de fontes primárias com análise crítica e descrição das } \\
\text { extensas contribuiçóes de James Parkinson (1755-1824), da } \\
\text { doença de Parkinson, para o cuidado clínico infantil e sua defesa } \\
\text { pioneira do bem-estar, proteção e segurança da criança. Ele foi } \\
\text { pioneiro na descriçáo de dados (em inglês) da fisiopatologia e } \\
\text { patologia da apendicite em crianças. }\end{array}$ \\
\hline
\end{tabular}




\begin{tabular}{|c|c|c|c|c|}
\hline 4 & $\begin{array}{l}\text { Validação do escore } \\
\text { de Alvarado no } \\
\text { diagnóstico de } \\
\text { apendicite aguda em } \\
\text { crianças e adolescentes } \\
\text { no Instituto } \\
\text { Materno Infantil de } \\
\text { Pernambuco, IMIP. }\end{array}$ & 2003 & $\begin{array}{l}\text { Artigo } \\
\text { original }\end{array}$ & $\begin{array}{l}\text { Estudo de validaçáa de método diagnóstico (escore clínico- } \\
\text { laboratorial para diagnóstico de apendicite aguda) tendo o } \\
\text { exame histopatológico como padráo ouro. A amostra estudada } \\
\text { consistiu de } 81 \text { crianças e adolescentes, admitidas na emergência } \\
\text { pediátrica do IMIP com dor abdominal suspeita de apendicite } \\
\text { aguda, no período de março a outubro de } 2002 \text {. Os pacientes } \\
\text { foram atendidos na emergência pediátrica e avaliados quanto ao } \\
\text { escore de Alvarado. Entretanto a decisão cirúrgica foi tomada } \\
\text { pelo cirurgião responsável. Teve como objetivo determinar a } \\
\text { acurácia do escore de Alvarado para o diagnóstico de apendicite } \\
\text { aguda em crianças e adolescentes admitidos na emergência do } \\
\text { Instituto Materno Infantil de Pernambuco (IMIP). }\end{array}$ \\
\hline 5 & $\begin{array}{l}\text { Apendicite aguda: } \\
\text { existe relaçáo entre o } \\
\text { grau evolutivo, idade e } \\
\text { o tempo de internação? }\end{array}$ & 2005 & $\begin{array}{l}\text { Artigo } \\
\text { original }\end{array}$ & $\begin{array}{l}\text { Análise retrospectiva de } 272 \text { pacientes submetidos à } \\
\text { apendicectomia quanto ao grau evolutivo da apendicite e seu } \\
\text { respectivo período de internaçáo. A evolução do processo } \\
\text { inflamatório foi classificada pelo exame histopatológico em } \\
\text { quatro graus: catarral, flegmonosa, supurativa e gangrenosa } \\
\text { com o objetivo de identificar uma possível relaçáo entre o grau } \\
\text { evolutivo da apendicite aguda, a idade cronológica e a duração } \\
\text { do período de internaçáo. }\end{array}$ \\
\hline 6 & $\begin{array}{l}\text { Apendicitis y } \\
\text { apendicectomías em } \\
\text { pediatria. Prevalencia } \\
\text { en un hospital de } \\
\text { segundo nivel. }\end{array}$ & 2014 & $\begin{array}{l}\text { Artigo } \\
\text { original }\end{array}$ & $\begin{array}{l}\text { Estudo retrospectivo do tipo coorte de pacientes pediátricos } \\
\text { operados de apendicite conduzido durante um período de } 3,5 \\
\text { anos. Foi investigado, entre outras coisas, idade de apresentaçáo, } \\
\text { dias de internaçáo, tempo de evoluçáo e morbidade. }\end{array}$ \\
\hline 7 & $\begin{array}{l}\text { Correlação entre a } \\
\text { Escala de Alvarado e o } \\
\text { aspecto macroscópico } \\
\text { do apêndice em } \\
\text { pacientes com } \\
\text { apendicite }\end{array}$ & 2014 & $\begin{array}{l}\text { Artigo } \\
\text { original }\end{array}$ & $\begin{array}{l}\text { O estudo teve como objetivo avaliar a possível associação entre } \\
\text { a escala de Alvarado (EA) e a aparência macroscópica (MA) } \\
\text { do apêndice em pacientes com apendicite aguda. Após receber } \\
\text { o diagnóstico de apendicite aguda, os dados da EA foram } \\
\text { coletados. Durante a apendicectomia, os dados MA foram } \\
\text { coletados. Dados de pacientes sem apendicite foram excluídos. } \\
\text { O teste de correlaçáo de Spearman foi usado para comparar } \\
\text { EA com o Apêndice MA (p <0,05). Outras variáveis foram } \\
\text { representadas por frequência simples. O intervalo de confiança } \\
\text { (IC) de } 95 \% \text { foi calculado para o teste de correlaçáa. }\end{array}$ \\
\hline 8 & $\begin{array}{l}\text { Escala de Alvarado para } \\
\text { o diagnóstico clínico de } \\
\text { apendicite aguda. }\end{array}$ & 2016 & $\begin{array}{l}\text { Revisão de } \\
\text { literatura }\end{array}$ & $\begin{array}{l}\text { Estudo observacional retrospectivo com recuperaçáo e análise } \\
\text { crítica da literatura com objetivo de apresentar uma proposta } \\
\text { de melhora na qualidade do atendimento ao paciente com } \\
\text { apendicite aguda, na pontualidade e eficiência diagnóstica e, } \\
\text { especialmente, no atendimento ambulatorial e de emergência, } \\
\text { onde não existem meios auxiliares de alto nível, como exames } \\
\text { de imagem. O estudo concluiu que a escala de Alvarado é útil } \\
\text { como ferramenta diagnóstica de apendicite aguda, tem alta } \\
\text { sensibilidade, boa especificidade e valor preditivo adequado. É } \\
\text { simples, confiável e não invasivo, de baixo custo e que pode ser } \\
\text { usado em serviços de emergência ou internaçáo. }\end{array}$ \\
\hline 9 & $\begin{array}{l}\text { Risk stratification to } \\
\text { decrease unnecessary } \\
\text { diagnostic imaging for } \\
\text { acute appendicitis. }\end{array}$ & 2016 & $\begin{array}{l}\text { Artigo } \\
\text { original }\end{array}$ & $\begin{array}{l}\text { Estudo prospectivo de série temporal interrompido comparando } \\
\text { o uso de imagens durante } 3 \text { períodos de tempo: linha de base } \\
\text { histórica, intervençáo passiva e intervenção ativa. O estudo foi } \\
\text { conduzido em um hospital terciário com um pronto-socorro } \\
\text { pediátrico com } 90.000 \text { visitas anuais e aproximadamente } 500 \\
\text { casos de apendicite por ano. Os grupos de risco moderado } \\
\text { e alto apresentaram proporçóes menores de tomografia } \\
\text { computadorizada (TC) nos períodos de intervençâo passiva } \\
\text { e ativa em comparaçâo com o grupo de controle histórico. } \\
\text { Proporçóes de pacientes submetidos a ultrassom em todos os } 3 \\
\text { grupos de risco mostraram um aumento em relação à linha de } \\
\text { base histórica. A análise de séries temporais confirmou que as } \\
\text { tendências temporais em qualquer período individual não eram } \\
\text { significativas; portanto, as tendências seculares incidentais ao } \\
\text { longo do tempo não parecem explicar o uso diminuído da TC. }\end{array}$ \\
\hline
\end{tabular}




\begin{tabular}{|c|c|c|c|c|}
\hline 10 & $\begin{array}{l}\text { Escore Alvarado } \\
\text { modificado em crianças } \\
\text { com diagnóstico de } \\
\text { apendicite. }\end{array}$ & 2017 & $\begin{array}{l}\text { Artigo } \\
\text { original }\end{array}$ & $\begin{array}{l}\text { Quatrocentos crianças com diagnóstico inicial de apendicite } \\
\text { foram selecionadas aleatoriamente de pacientes submetidos } \\
\text { à apendicectomia. A pontuaçáo de Alvarado modificada foi } \\
\text { utilizada para avaliaçáo do quadro, que foi confirmado por meio } \\
\text { de histologia. O objetivo do estudo foi de avaliar a sensibilidade, } \\
\text { especificidade, valor preditivo positivo e valor preditivo negativo } \\
\text { do escore de Alvarado modificado em crianças submetidas à } \\
\text { apendicectomia. }\end{array}$ \\
\hline 11 & $\begin{array}{l}\text { Fatores de risco } \\
\text { associados às } \\
\text { complicaçôes de } \\
\text { apendicite aguda. }\end{array}$ & 2017 & $\begin{array}{l}\text { Artigo } \\
\text { original }\end{array}$ & $\begin{array}{l}\text { Estudo de caso controle com o objetivo de identificar os } \\
\text { principais fatores de risco associados ao desenvolvimento de } \\
\text { complicaçóes em pacientes portadores de apendicite aguda a } \\
\text { partir de dados dos prontuários de } 402 \text { pacientes internados } \\
\text { com apendicite aguda em um hospital de nível secundário, } \\
\text { separados em dois grupos: grupo controle, com } 373 \text { pacientes } \\
\text { que evoluíram sem complicaçóes pós-operatórias (Grupo 1) e } \\
\text { grupo estudo, com } 29 \text { pacientes que apresentaram complicaçôes } \\
\text { (Grupo 2). Foram avaliados dados demográficos, sinais e } \\
\text { sintomas da doença, exames de imagem e dados da internaçáo. }\end{array}$ \\
\hline 12 & $\begin{array}{l}\text { A clinical score to } \\
\text { predict appendicitis in } \\
\text { older male children }\end{array}$ & 2017 & $\begin{array}{l}\text { Artigo } \\
\text { original }\end{array}$ & $\begin{array}{l}\text { Estudo observacional com objetivo de desenvolver um escore } \\
\text { clínico para predizer apendicite em crianças mais velhas do } \\
\text { sexo masculino que se apresentam ao pronto-socorro com } \\
\text { suspeita de apendicite. Pacientes com suspeita de apendicite } \\
\text { foram incluídos prospectivamente em } 9 \text { departamentos de } \\
\text { emergência pediátrica. Um total de } 2.625 \text { pacientes inscritos; } \\
\text { um subconjunto de } 961 \text { pacientes do sexo masculino, com } \\
\text { idades entre } 8 \text { e } 18 \text { anos, foi analisado nesta análise secundária. } \\
\text { Os resultados foram determinados usando patologia, relatórios } \\
\text { cirúrgicos e chamadas de acompanhamento. Preditores clínicos } \\
\text { e laboratoriais com < } 10 \% \text { de dados ausentes e kappa> } 0,4 \\
\text { foram inseridos em um modelo multivariável. Os coeficientes } \\
\bigotimes \text { resultantes foram usados para desenvolver uma pontuaçáo } \\
\text { clínica. O desempenho do teste foi avaliado calculando a } \\
\text { sensibilidade, especificidade, valor preditivo positivo, valor } \\
\text { preditivo negativo e razóes de probabilidade. }\end{array}$ \\
\hline 13 & $\begin{array}{l}\text { Bacterial culture and } \\
\text { antibiotic susceptibility } \\
\text { in patients with acute } \\
\text { appendicitis }\end{array}$ & 2018 & $\begin{array}{l}\text { Artigo } \\
\text { original }\end{array}$ & $\begin{array}{l}\text { Com a premissa de que, para tratar a apendicite aguda com } \\
\text { eficácia, é importante identificar o microrganismo da apendicite } \\
\text { aguda e avaliar os antibióticos eficazes, os autores selecionaram } \\
694 \text { pacientes submetidos à apendicectomia por apendicite } \\
\text { aguda e com resultado microbiano positivo entre } 2006 \text { e } 2015 \text {. } \\
\text { Para avaliaçáo microbiana, o conteúdo luminal do apêndice foi } \\
\text { esfregado após a apendicectomia. Em pacientes com abscesso } \\
\text { periapendicular, as amostras foram obtidas do fluido de } \\
\text { abscesso. As características do paciente, dados operatórios, uso } \\
\text { de antibióticos, os resultados da microbiologia e morbidades } \\
\text { pós-operatórias, incluindo infecçáo de sítio cirúrgico (ISC) } \\
\text { foram revisados retrospectivamente. }\end{array}$ \\
\hline 14 & $\begin{array}{l}\text { Associaçáo entre o } \\
\text { escore de Alvarado, } \\
\text { achados cirúrgicos e } \\
\text { aspecto histopatológico } \\
\text { da apendicite aguda. }\end{array}$ & 2018 & $\begin{array}{l}\text { Artigo } \\
\text { original }\end{array}$ & $\begin{array}{l}\text { Estudo observacional de delineamento transversal de } 101 \\
\text { pacientes com } 14 \text { anos de idade ou mais, submetidos à } \\
\text { apendicectomia de urgência. A avaliaçáo continha o escore de } \\
\text { Alvarado, pontuaçáa no escore, sexo, idade, etnia dos pacientes } \\
\text { e tempo de evoluçấo. Foi obtido o aspecto cirúrgico do } \\
\text { apêndice, dados a respeito das complicaçóes pós-operatórias e } \\
\text { o resultado do exame histopatológico. O intervalo de confiança } \\
\text { pré-estabelecido foi de } 95 \% \text {. Foram calculadas sensibilidade, } \\
\text { especificidade, valor preditivo positivo e negativo do escore, e } \\
\text { realizada uma análise através da curva ROC. Teve como objetivo } \\
\text { comparar o resultado do escore de Alvarado com os achados } \\
\text { cirúrgicos e com os resultados do exame histopatológico do } \\
\text { apêndice de pacientes operados por apendicite aguda. }\end{array}$ \\
\hline
\end{tabular}




\begin{tabular}{|l|l|l|l|l|}
\hline 15 & $\begin{array}{l}\text { Correlation of clinical } \\
\text { data and the Alvarado's } \\
\text { Score as predictors of } \\
\text { acute appendicitis. }\end{array}$ & 2018 & $\begin{array}{l}\text { Artigo } \\
\text { original }\end{array}$ & $\begin{array}{l}\text { Trata-se de um estudo observacional, descritivo e prospectivo } \\
\text { realizado em um hospital público de urgência e emergência } \\
\text { da cidade de Fortaleza, Ceará, entre julho e dezembro de } \\
\text { 2016, com 34 pacientes submetidos à apendicectomia aberta } \\
\text { com idades entre 18 e } 70 \text { anos. O objetivo do estudo foi de } \\
\text { Correlacionar os dados clínicos do paciente e a pontuaçáo de } \\
\text { Alvarado como preditores de apendicite aguda. }\end{array}$ \\
\hline 16 & $\begin{array}{l}\text { Apendicite em } \\
\text { pediatria: a idade é } \\
\text { importante }\end{array}$ & $\begin{array}{l}\text { Com objetivo de investigar a influência da idade do paciente } \\
\text { no diagnóstico e tratamento de apendicite, bem como } \\
\text { avaliar a frequência de complicaçóes dependendo da faixa } \\
\text { etária, foi realizada uma análise retrospectiva dos } \\
\text { pacientes pediátricos que foram submetidos à apendicectomia } \\
\text { laparoscópica em um hospital terciário no período de janeiro } \\
\text { de 2000 a dezembro de 2013. Os pacientes foram divididos } \\
\text { em grupos de acordo com sua idade: grupo A eram crianças, } \\
\text { grupo B eram pré-escolares, grupo C eram maiores de cinco } \\
\text { anos de idade e grupo D eram menores de cinco anos de idade. } \\
\text { Considerou-se estatisticamente significante p-valor }<0,05 .\end{array}$ \\
\hline
\end{tabular}

Conforme explica Cerruti ${ }^{9}$, a inflamação aguda do apêndice causa lesôes, que são simples a princípio, mas que se tornam, em poucas horas, progressivamente mais graves, fornecendo diferentes classificaçôes anatomopatológicas, que correspondem a sucessão dos estádios da inflamação do órgão. Assim são descritas pelo autor:

A lesão inicial (primaerdefetke) localiza-se numa cripta ou dobra profunda da mucosa do apêndice. Através desta erosão há invasão da parede do órgão por um processo inflamatório que se estende, em forma de cunha, mais na camada muscular e serosa do que propriamente na mucosa e submucosa. Tal alteração microscópica corresponde macroscopicamente a um apêndice apenas hiperemiado ou mesmo de aspeto normal. Esta é a apendicite catarral. Com o progredir do processo há generalização da inflamaçáo com acometimento de outras criptas e das diversas túnicas do apêndice que, inteiramente infiltrado por um exsudato de polinucleares neutrófilos, constitui o quadro da apendicite flegmonosa. [...] Em fases mais adiantadas aparecem as formas complicadas de apendicite aguda. Há, então, fluidificação purulenta com formação de abcessos na parede do apêndice que se podem abrir na sua luz ou através da serosa e, à custa de perfuraçóes muito pequenas, contaminar amplamente o peritônio. É a apendicite supurada perfurada. Por fim, em certos casos há edema e inflamação do mesoapêndice, trombose da artéria apendicular que sendo terminal ocasiona a gangrena do apêndice em extensão variável. É a apendicite gangrenosa com perfuração do órgão. Constitui esta, a modalidade mais grave de apendicite ${ }^{8}$.

Dessa forma, com relação a descrição histopatológica, uma referência é a classificação citada por Fisher $e t$ al $l^{10}$, em grau de evolução, como: fase catarral (grau 1); fase flegmonosa (grau 2); fase supurativa (grau 3) e fase gangrenosa (grau 4). Já a descrição macroscópica do apêndice pode ser realizada segundo os critérios descritos no estudo de Souza-Rodrigues et al. ${ }^{10}$, nos seguintes graus: 1) apêndice sem perfuração e modificações mínimas; 2) apêndice sem perfuração e a presença de gangrena supuração 
ou necrose; 3) apêndice com perfuração e peritonite ou abscesso no local; e 4) apêndice com perfuração e peritonite difusa.

Borges, Lima e Falbo Neto $^{12}$ dizem que a apendicite acomete mais o sexo masculino, na razão de 3:2, sendo observada uma maior incidência em familiares. Conforme explicam os pesquisadores Aneiros et al. ${ }^{13}$, a idade faz diferença no diagnóstico em casos de apendicite aguda, pois se verifica que, devido a sua apresentaçáo ser rara em crianças menores de 5 anos, é frequentemente diagnosticada de forma incorreta, o que aumenta sua morbidade. No estudo desses autores, apesar de sua apresentação clínica variar entre lactentes e préescolares, os pesquisadores não observaram diferenças estatisticamente significativas na proporçáo de apêndices perfurados nem na de complicaçóes pós-operatórias.

É de conhecimento médico que o diagnóstico da apendicite aguda é clínico. Uma boa anamnese e um exame físico adequado poderão ser resolutivos para a descoberta precoce. Porém, o uso de ferramentas como os exames de imagem está cada vez mais comum nos prontos atendimentos do Brasil. Nesse sentido, o exame radiológico tem um papel limitado, enquanto a ultrassonografia (USG) possui como vantagem ser um procedimento não invasivo, que não há exposição do paciente a radiação, todavia, ela não fornece uma imagem bem definida, principalmente em pacientes obesos e quando as alças intestinais estáo distendidas além de necessitar de examinador com habilidade e experiência ${ }^{8}$.

O diagnóstico incorreto é mais comum em crianças e idosos, e seu diagnóstico tardio não é muito incomum, devido apresentação atípica na doença com $40 \%$ das crianças diagnosticadas incorretamente, por isto se apresenta como desafio aos profissionais. A apendicite descoberta de forma tardia representa progressóes patológicas graves, relacionada a complicaçóes sistêmicas, maior tempo de hospitalização, aumento de morbidades e/ou mortalidade, representando maiores custos ao sistema público de saúde, e perda de vidas, onerando assim os serviços de saúde ${ }^{14}$.

Além disso, cada vez mais o uso do estudo clínico através da anamnese e do exame físico vem sendo abandonado pelos profissionais, seja por insegurança ou despreparo. Com isso, há um aumento excessivo do uso de exame radiológico nos hospitais pediátricos. $\mathrm{O}$ uso da tomografia computadorizada (TC) já representa $21 \%$ a $49 \%$ dos casos. Segundo estudo realizado por Kharbandaet al. ${ }^{15}$, o potencial de uso de TC é problemático, devido a riscos com a radiação, por indução de malignidade, principalmente em mulheres jovens. Assim, é consenso limitar seu uso.

Uma opçáo é o uso da escala de Alvarado para o diagnóstico de apendicite aguda. Incluem-se nesta escala parâmetros sintomatológicos e laboratoriais com diferentes pontuaçóes; dor migratória em fossa ilíaca direita (1), náuseas e/ou vômitos (1), febre (1), anorexia (1), defesa em parede em quadrante inferior direito (QID) (2), dor a descompressão (1), Leucocitose $>10.000$ (2) e desvio à esquerda (1). Observa-se que 
cada característica vale um (1) ponto, exceto a leucocitose e a defesa emparede em QID, os quais valem dois (2), totalizando assim 10 pontos $^{8}$.

Em relação ao escore de Alvarado, Adorno et al. ${ }^{8}$ explicam que aqueles que apresentarem pontuação maior ou igual a 7 possuem indicação de tratamento cirúrgico; quando entre 5 e 6 , a probabilidade de apendicite aguda é alta, portanto, é indicada a realização de exames de imagens simples, como USG ou TC para confirmar o diagnóstico; se a pontuação for menor que 4 , a probabilidade de apendicite é baixa. Cabe ressaltar que a inflamação do apêndice raramente se apresenta com pontuação menor que 4.

Segundo Depinet et al. ${ }^{16}$, muito embora a precisão dos fatores clínicos para o diagnóstico de apendicite seja relatada em 70\% a 87\%, o uso de imagens de diagnóstico, incluindo a TC, se generalizou. Apesar da recomendação atual de ultrassom como o exame preferido para diagnóstico por imagem de apendicite, e o pequeno aumento do risco de malignidade ao longo da vida associado à radiação ionizante, a TC ainda é comumente usada em algumas áreas para diagnóstico por imagem nesses casos.

Borges, Lima e Falbo Neto ${ }^{12}$ utilizaram uma amostra de 81 crianças e adolescentes, tendo como ponto de corte o valor $>5$. Os resultados de seu estudo demonstraram que o escore de Alvarado é um procedimento pouco invasivo, simples, rápido e reprodutível, e tendo como escore mínimo 5 pontos, se apresenta como um instrumento de alto valor na triagem de crianças e adolescentes com suspeita diagnóstica de apendicite aguda.

Da mesma forma, o estudo realizado por Cunha et al. ${ }^{17}$ também avaliou a eficácia do escore de Alvarado, em um hospital de urgência e emergência na cidade de Fortaleza, concluindo que seu uso nos serviços de saúde surge como uma ferramenta acessível e eficaz para otimizar a abordagem de pacientes com um quadro sugestivo de apendicite. Além disso, o escore de Alvarado também pode sugerir o grau de inflamação do apêndice. Os autores também lembram que quanto mais rápida a definição terapêutica da apendicite aguda, menor a chance de ocorrência de necrose ou formaçáo de abscesso no apêndice e menor a duração da internação hospitalar no período pós-operatório.

Com relação aos sinais clínicos, no estudo realizado por De Nascimento et al. ${ }^{7}$, o sintoma mais frequente foi a dor à descompressão, apresentada por $92 \%$ dos pacientes avaliados, seguida pela leucocitose em $84,2 \%$ dos pacientes, anorexia em 77,2\% e náuseas e vômitos em 75,2\%. Os menos frequentes foram a dor migratória em 56,4\%, defesa em parede em QID em 47,5\%, febre em 38,6\%, e desvio à esquerda ao leucograma em $15,8 \%$ dos pacientes avaliados.

No estudo de Souza-Rodrigues et al. ${ }^{11}$, o sintoma mais frequente entre os pacientes avaliados foi a defesa em parede em QID, apresentada por $91 \%$ (61 em 67) dos pacientes, seguida pela febre em 85,1\% (57/67), anorexia em 85,1\% (57/67), leucocitose em 83,6\% (56/67), náuseas e vômitos em 80,6\% (54/67) e dor a descompressão em 62,7\% (42/67). 
Já no estudo realizado por Iamarino $e t a l .^{14}$, o sintoma mais frequentemente diagnosticado foi a dor migratória, encontrada em $96 \%$ dos pacientes que apresentaram apendicite sem complicação e, em $93 \%$ dos que apresentaram apendicite com complicação. Entre as complicaçôes, que são decorrentes da evoluçáo do processo inflamatório agudo, os autores citam: supuraçáo, perfuração com ou sem hemorragia e gangrena do apêndice.

A dor a descompressáo foi o segundo sintoma mais comum do estudo de Iamarino et al. ${ }^{14}$, apresentada por $80 \%$ dos pacientes sem complicações, e por $93 \%$ dos pacientes com complicaçóes. Em seguida, náuseas e vômitos foram apresentados por $73 \%$ dos pacientes sem complicaçôes, e por $83 \%$ daqueles com complicaçôes. Em relaçáo a febre, $44 \%$ dos pacientes sem complicaçóes apresentaram esse sintoma, enquanto $72 \%$ daqueles que tinham complicaçōes também tinham febre. Cabe ressaltar que os autores não avaliaram os demais sintomas do Escore de Alvarado, trazendo apenas os resultados já citados.

Em outro estudo, realizado por Peyvasteh et al. ${ }^{5}$, o sintoma mais comum foi a defesa em parede em QID, encontrada em 91,4\% dos pacientes. Em seguida veio a leucocitose, demonstrada por $89,3 \%$ dos pacientes. A sintomatologia de náuseas e vômitos foi a terceira mais frequente, com $84,3 \%$ deles apresentando esses sintomas. A anorexia foi encontrada em $73,6 \%$ dos pacientes, e a febre foi a menos frequente, sendo verificada em $49,3 \%$ dos pacientes avaliados pelos autores. Todavia, assim como no estudo de Iamarino et al. ${ }^{14}$, esses autores também não avaliaram os demais sintomas do Escore de Alvarado.

Sendo assim, ao comparar os resultados dos estudos de Peyvasteh et al..$^{5}$, Do Nascimento et al. , Iamarino et al. ${ }^{14}$ e Souza-Rodrigues et al. ${ }^{11}$, observa-se que existem variaçóes entre as frequências encontradas dos sintomas apresentados pelos pacientes, porém algumas concordâncias foram encontradas, podendo-se citar os sintomas de náuseas e vômitos, dor a descompressáo e leucocitose como os mais frequentemente encontrados, enquanto a dor migratória em fossa ilíaca direita e o desvio a esquerda ao leucograma seriam os menos comuns.

\section{CONCLUSÓES}

Através dos dados aqui apresentados pode-se concluir que o uso do Escore de Alvarado para o diagnóstico de apendicite aguda em crianças é útil e eficaz, evitando-se o uso de exames de imagem em pacientes que apresentem escore acima de 7.

Portanto, em caso de abdome agudo em crianças, não se deve realizar exames de imagem sem necessidade, visto que quando o escore de Alvarado é igual ou acima de 7 já é indicativo de cirurgia, portanto, tais exames sâo desnecessários. Caso ainda assim seja desejável uma confirmaçáo, em especial quando em crianças com menos de 5 anos 
de idade, onde o diagnóstico é menos preciso, o exame de escolha deve ser a USG, não sendo indicados exames como radiografia e TC pela exposição das crianças à radiação ionizante.

\section{REFERENCIAS}

1. Arredondo GP. Apendicitis y apendicectomías em pediatria. Prevalencia en un hospital de segundo nivel. Cir Gen. 2014;3(2):82-86. Acesso em: 25 dez 2020. Disponívelem:http://www.scielo.org.mx/scielo.php?script=sci_ arttext\&pid=S1500992014000200082\&lng=es\&nrm=iso.

2. Lima AP, Vieira FJ, Oliveira GP De M, Ramos P Dos S, Avelino ME et al. Perfil clínico-epidemiológico da apendicite aguda: análise retrospectiva de 638 casos. Rev. Col. Bras. Cir. [Internet]. 2016 Ago [citado 2021 Jan 24] ; 43( 4 ): 248-253.Disponívelem:http://www.scielo.br/scielo. php?script=sci_arttext\&pid=S010069912016000400248\&lng=pt.http://dx.doi. org/10.1590/01006991201600400.

3. Pearn J, Gardner-Thorpe C. James Parkinson (1755-1824): a pioneer of child care. J Paediatr Child Health. 2001;37(1):9-13.https://doi.org/10.1046/j.14401754.2001.00598.x.

4. Parkinson J. Case of diseased vermiform appendix. Med. Chirurg. Trans. 1812;3:57.Acesso em: 25 dez 2020. Disponível em: https://www.ncbi.nlm.nih.gov/ pmc/articles/PMC2128895/.

5. Peyvasteh M, Askarpour S, Javaherizadeh H, Besharati S. Escore Alvarado modificado em crianças com diagnóstico de apendicite. ABCD, arq. bras. cir. dig. 2017; 30(1):51-52. https://doi.org/10.1590/0102-6720201700010014.

6. Song DW, Park BK, Suh SW, Lee SE, Kim JW, Park JM, et al. Bacterial culture and antibiotic susceptibility in patients with acute appendicitis. Int J Colorectal Dis. 2018;4(33):441-447. https://doi.org/10.1007/s00384-018-2992-z.

7. Do Nascimento RR, Souza JCG, Alexandre VB, Kock KS, Kestering DM. Associação entre o escore de Alvarado, achados cirúrgicos e aspecto histopatológico da apendicite aguda. Rev. Col. Bras. Cir. 2018;45(5):e1901. http://dx.doi. org/10.1590/0100-6991e-20181901.

8. Adorno GR, Rios TF, Colombo FAA, Cuellar PMG. Escala de Alvarado para o diagnóstico clínico de apendicite aguda. Rev Pato Tocantins. 2016;3(2):46-52. Acesso em: 25 dez 2020. Disponível em: https://sistemas.uft.edu.br/periodicos/index.php/ patologia/article/view/2094. 
9. Cerruti F. A apendicite na síndrome de abdômen agudo. Rev Med.

1942;26(99):5-36. https://doi.org/10.11606/issn.1679-9836.v26i99p5-36.

10. Fischer CA, Pinho MSL, Ferreira S, Milani CAC, van Santen CR, Marquardt RA. Apendicite aguda: existe relaçáo entre o grau evolutivo, idade e o tempo de internação?Rev.Col.Bras.Cir.2005;32(3):136-138.https://doi.org/10.1590/S010069912005000300007.

11. Souza-Rodrigues CF, Rocha AC, Rodrigues AKB, Barbosa FT, Ramos FWS, Valóes SHC. Correlação entre a Escala de Alvarado e o aspecto macroscópico do apêndice em pacientes com apendicite. Rev. Col. Bras. Cir. 2014;41(5):336-340. https://doi.org/10.1590/0100-69912014005007.

12. Borges PSGN, Lima MC, Falbo Neto GH. Validação do escore de Alvarado no diagnóstico de apendicite aguda em crianças e adolescentes no Instituto Materno Infantil de Pernambuco, IMIP. Ver. Bras. Saúde Matern. Infant. 2003;3(4):439-445. https://doi.org/10.1590/S1519-38292003000400008.

13. Aneiros B, Cano I, García A, Yuste P, Ferrero E, Gómez A. Apendicite em pediatria: a idade é importante. Rev. paul. pediatr. 2019;37(3):318-324. https://doi. org/10.1590/1984-0462/;2019;37;3;00019.

14. Iamarino APM, Juliano Y, Rosa OM, Novo NF, Favaro ML, Ribeiro Júnior MAF. Fatores de risco associados às complicaçóes de apendicite aguda. Rev. Col. Bras. Cir. 2017;44(6):560-566. https://doi.org/10.1590/0100-69912017006002.

15. Kharbanda AB, Monuteaux MC, Bachur RG, Dudley NC, Bajaj L, Stevenson $\mathrm{MD}$, et al. A clinical score to predict appendicitis in older male children. Acad Pediatr. 2017;17(3):261-266. https://doi.org/10.1016/j.acap.2016.11.014.

16. Depinet H, von Allmen D, Towbin A, Hornung R, Alessandrini E. Risk stratification to decrease unnecessary diagnostic imaging for acute appendicitis. Pediatrics. 2016;138(3):e20154031. https://doi.org/10.1542/peds.2015-4031.

17. Cunha CMQ, Troiani Neto G, Brasil AC, Menezes FJC, Brilhante AVM, Reinaldo RRP. Correlation of clinical data and the Alvarado's Score as predictors of acute appendicitis. J. Coloproctol. 2018;38(2):95-98. https://doi.org/10.1016/j. jcol.2017.11.004.

Autor Correspondente: Bruno César Fernandes

E-mail: brunoanaisafernandes@gmail.com

Recebido em: 2020-12-10

Aprovado em: 2020-12-19 